Check for updates

Cite this: RSC Adv., 2020, 10, 40321

Received 9th September 2020

Accepted 29th October 2020

DOI: $10.1039 / \mathrm{dOra07745c}$

rsc.li/rsc-advances

\section{Study of enantioselective metolachlor adsorption by activated carbons $\uparrow$}

\author{
Alicia Gomis-Berenguer, (D) *a Isabelle Laidin, ${ }^{\text {b }}$ Sophie Renoncial ${ }^{\mathrm{b}}$ \\ and Benoît Cagnon*a
}

Four activated carbons were employed to analyse the adsorption of different enantiomeric mixtures of the herbicide metolachlor in aqueous solution. The adsorption kinetics and isotherms were measured and fitted with different theoretical models to exhaustively analyse the adsorption mechanism. Different adsorption capacities were observed as a function of textural features of the adsorbents revealing an important effect of the presence of micro and mesoporous development on the adsorbent-adsorbate interactions. Additionally, enantioselective adsorption was detected for two of the activated carbons employed, rendering a greater adsorption of the $S$-metolachlor enantiomer compared to the racemic mixture. This fact was associated to the accessibility of certain conformers of the herbicide to the larger pores, facilitating the non-electrostatic adsorption.

\section{Introduction}

The pollution caused by pesticides has greatly increased due to their widespread use in agriculture around the world. Pesticides are highly noxious, sometimes non-biodegradable and very mobile throughout the environment (water and soils). For the above reasons, the scientific community is focused on the removal of these toxic pollutants from aqueous solutions by different mechanisms such as photocatalysis, ${ }^{1,2}$ adsorption, ${ }^{3-5}$ and electrochemical processes. ${ }^{6,7}$ Specifically, adsorption is highly used in drinking water treatment plants due to its low cost, high removal efficiency and easy operation compared to other techniques.

Metolachlor is a very widely used herbicide for selective leaf weed control in more than 70 crops. $^{8}$ It belongs to the acetamide class of chiral herbicides and contains $R$ - (R-MET) and $S$ - (S-MET) enantiomers (present in equal ratio for racemic metolachlor, RacMET). Moser et al. ${ }^{9}$ reported that the $S$-enantiomer presents highest herbicidal efficiency, while the $R$-enantiomer possesses a superior fungicidal activity. Consequently, in many countries the use of racemic herbicide was forbidden and replaced by $S$-metolachlor, particularly, in France the use of racemic metolachlor was banned on 2003. ${ }^{10}$ Since the rate of dissipation and soil binding of both enantiomers is the same, ${ }^{11}$ this led to a reduction in the doses applied by farmers, maintaining the biological performance, and is expected to result in lower concentrations of the residues in the environment. However, due to its extensive use, high water

anterfaces, Confinement, Matériaux et Nanostructures-ICMN, UMR 7374-CNRS, Université d'Orléans, 1B, Rue de La Férollerie, CS 40 059, 45071 Orléans Cedex 2, France.E-mail: aliciagb@kth.se; benoit.cagnon@univ-orleans.fr

${ }^{b} J A C O B I$ Carbons, 15 Route de Foëcy, 18100 Vierzon, France

$\dagger$ Electronic supplementary information (ESI) available. See DOI: 10.1039/d0ra07745c solubility, low vapour pressure, and long-life, metolachlor can be widely detected in surface water and groundwater compromising the water quality. ${ }^{12}$

Although R-MET and S-MET adsorption has been extensively studied, ${ }^{3,5,13}$ specific data for selective adsorption of each enantiomer are scarce. To the best of the authors' knowledge, this work analyses for the first time, the selective adsorption of both enantiomers employing three commercial activated carbons and one activated carbon elaborated from agricultural residues as adsorbents.

\section{Experimental section}

\subsection{Materials}

Rac-metolachlor and enriched $S$-metolachlor $(60 \%)$ were purchased from Sigma-Aldrich, pure $S$-metolachlor $(100 \%)$ was purchased from LGC Standards. For clarity, the physicochemical properties including the molecular structure of each enantiomer are shown in Table 1 . The chemicals were used without further purification. All solutions were prepared with ultra-pure water obtained from Milli-Q water purification systems.

Three commercial granular activated carbons (L27, AQ630 and S21) were supplied by Jacobi Carbons (Vierzon, France). The materials were grinded to obtain a particle size $c a .<80 \mu \mathrm{m}$ and washed with distilled water until constant $\mathrm{pH}$ to remove the residual activating agent. Additionally, an activated carbon obtained by chemical activation from a lignocellulosic precursor (rape straw) was also employed. The material (named as R-KC) was synthesized by chemical activation, briefly $1 \mathrm{~g}$ of rape straw powder was physically impregnated with $1 \mathrm{~g}$ of $\mathrm{K}_{2} \mathrm{CO}_{3}$ in a mortar, then the activation was performed at $800{ }^{\circ} \mathrm{C}$ for $1 \mathrm{~h}$ 
Table 1 Physicochemical properties of $R$ - and S-metolachlor

\begin{tabular}{|c|c|c|}
\hline & $R$-Metolachlor & $S$-Metolachlor \\
\hline Molecular formulae & $\mathrm{C}_{15} \mathrm{H}_{22} \mathrm{ClNO}_{2}$ & $\mathrm{C}_{15} \mathrm{H}_{22} \mathrm{ClNO}_{2}$ \\
\hline IUPAC name & $\begin{array}{l}\text { 2-Chloro- } N \text {-(2-ethyl-6-methylphenyl)- } N-[(2 R)-1 \text { - } \\
\text { methoxypropan-2-yl] acetamide }\end{array}$ & $\begin{array}{l}\text { 2-Chloro- } N \text {-(2-ethyl-6-methylphenyl)- } N \text { - } \\
{[(2 S) \text {-1-methoxypropan-2-yl]acetamide }}\end{array}$ \\
\hline CAS number & $178961-20-1$ & $87392-12-9$ \\
\hline Molecular weight $\left(\mathrm{g} \mathrm{mol}^{-1}\right)$ & 283.79 & 283.79 \\
\hline Water solubility at $25^{\circ} \mathrm{C}\left(\mathrm{mg} \mathrm{L}^{-1}\right)^{14}$ & 480 & 480 \\
\hline \multicolumn{3}{|l|}{ Molecular structure } \\
\hline
\end{tabular}

under $\mathrm{N}_{2}$ flow of $160 \mathrm{~mL} \mathrm{~min}^{-1}$ (heating rate $10{ }^{\circ} \mathrm{C} \mathrm{min}^{-1}$ ) in an horizontal furnace. After cooling under a $\mathrm{N}_{2}$ flow, the material was thoroughly washed with distilled water until constant $\mathrm{pH}$ to remove any water-soluble species and the excess of oxidising agent, dried at $60{ }^{\circ} \mathrm{C}$ overnight and stored in a desiccator.

\subsection{Characterization of the adsorbents}

The porosity of the materials was characterized by measuring the $\mathrm{N}_{2}$ adsorption/desorption isotherms at $77 \mathrm{~K}$ (ASAP 2020, Micromeritics). The materials were previously outgassed under vacuum $\left(\mathrm{ca} .10^{-4} \mathrm{~Pa}\right)$ at $120^{\circ} \mathrm{C}$ for $17 \mathrm{~h}$. The isotherms were used to determine several textural parameters as specific surface area $\left(S_{\mathrm{BET}}\right)$, specific total pore volume $\left(V_{\text {total }}\right)$, specific micro- and meso-pores volumes $\left(W_{0}, W_{\text {meso }}\right)$ and mean micropore size $(L)$. The surface $\mathrm{pH}$ was determined measuring the $\mathrm{pH}$ of an equilibrated aqueous suspension (ca. $1 \mathrm{~g} \mathrm{~L}^{-1}$ ) of the adsorbent. Elemental analysis was carried out by Thermo Scientific FLASH 2000 automatic analyser. TEM (transmission electron microscopy) images were obtained by a microscope (Philips CM20, Philips Co. Ltd.) operating at $200 \mathrm{kV}$.

\subsection{Adsorption experiments}

To study the adsorption kinetics experiments, a solution volume of $100 \mathrm{~mL}$ of each compound with an initial concentration of $25 \mathrm{mg} \mathrm{L}^{-1}$ was mixed with $5 \mathrm{mg}$ of adsorbent $(0.5 \mathrm{mg}$ compound per $\mathrm{mg}$ adsorbent) in glass flasks and continuously stirred $(400 \mathrm{rpm})$ on a multi-stirring plate (IKA brand) at $25{ }^{\circ} \mathrm{C}$ in a thermostatic water bath. Aliquots were measured at specific time intervals until equilibrium was reached. Solutions were filtered through a Nylon syringe filter $(0.45 \mu \mathrm{m})$ and the concentration was determined by reverse-phase HPLC in an apparatus equipped with a photodiode array detector (Shimadzu Nexera XR). A C-18 column (Restek) with a particle size of $2.7 \mu \mathrm{m}(3 \mathrm{~mm} \times 100 \mathrm{~mm})$ was employed. As a mobile phase water : acetonitrile $(40: 60 \mathrm{v} / \mathrm{v})$ was used at a flow rate of 0.8 $\mathrm{mL} \mathrm{min}^{-1}$. The column was thermostated at $30{ }^{\circ} \mathrm{C}$ and the sample injection volume was $50 \mu \mathrm{L}$. Both metolachlor enantiomers ( $R$ - and $S$-) were detected at wavelength of $230 \mathrm{~nm}$ after $5.5 \mathrm{~min}$ (no chiral separation was produced). An example of racemic metolachlor's chromatogram is shown in Fig. S1 ESI. $\dagger$ LabSolutions software from Shimadzu was used for identification and quantification of the molecule. The concentration of the compound was calculated based on the relative peak areas using standards of known concentrations. Equilibrium adsorption isotherms were also carried out from $25 \mathrm{~mL}$ of solutions of initial concentration ranging from 20 to $150 \mathrm{mg} \mathrm{L}^{-1}$ with $2.5 \mathrm{mg}$ of adsorbent (0.2-1.5 mg compound per $\mathrm{mg}$ adsorbent) during $24 \mathrm{~h}$ (equilibrium time based on the kinetic study). All adsorption assays were made by duplicate and a blank solution (without adsorbent) was used to check the adsorption of the sorbate on the walls.

The amount of compound adsorbed was determined following the equation: ${ }^{15}$

$$
q_{t}=\frac{C_{0}-C_{t}}{W} \times V
$$

where $q_{t}$ is the amount adsorbed $\left(\mathrm{mg} \mathrm{g}^{-1}\right)$ at time $t, C_{0}$ and $C_{t}$ are the compound concentrations $\left(\mathrm{mg} \mathrm{mL}^{-1}\right)$ in the initial solution and at time $t$ respectively, $V$ is the volume $(\mathrm{mL})$ of the solution and $W$ is the weight (g) of adsorbent. The removal efficiency percentage was calculated by:

$$
\operatorname{Removal}(\%)=\frac{C_{0}-C_{\mathrm{e}}}{C_{0}} \times 100
$$

where $C_{0}$ and $C_{\mathrm{e}}$ are the concentration of the compound before and after adsorption respectively. ${ }^{15}$

\subsection{Data modelling analysis}

Lagergren pseudo-first order ${ }^{\mathbf{1 6}}$ and Ho's pseudo-second order $^{17,18}$ models were applied to describe the kinetics adsorption of the molecules. The values of rate constants and the amounts of adsorption at equilibrium were determined by the non-linear method using Origin software. The pseudo-first order kinetic equation is expressed as: 


$$
q_{t}=q_{\mathrm{e}}\left(1-\mathrm{e}^{-k_{1} t}\right)
$$

where $k_{1}$ is the rate constant of pseudo-first order adsorption in $\left(\mathrm{h}^{-1}\right), q_{\mathrm{e}}$ is the amount of solute adsorbed at equilibrium in ( $\mathrm{mg}$ $\mathrm{g}^{-1}$ ) and $t$ the time in (h).

The pseudo-second order kinetic equation is expressed as follows:

$$
q_{t}=\frac{k_{2} \times q_{\mathrm{e}}^{2} \times t}{1+k_{2} \times q_{\mathrm{e}} \times t}
$$

where $k_{2}$ is the rate constant of pseudo-second order adsorption in $\left(\mathrm{g} \mathrm{mg}^{-1} \mathrm{~h}^{-1}\right)$.

The adsorption mechanism was analysed applying to the data the Morris-Weber equation: ${ }^{19}$

$$
q_{t}=k_{\mathrm{p}} \times t^{\frac{1}{2}}+C
$$

where $q_{t}$ is the amount adsorbed at time $t\left(\mathrm{mg} \mathrm{g}^{-1}\right), k_{\mathrm{p}}$ is the rate constant of intraparticle diffusion $\left(\mathrm{mg} \mathrm{g}^{-1} \mathrm{~h}^{-1 / 2}\right)$ and $C$ is the intercept which is related to boundary layer thickness.

The equilibrium experimental adsorption data were fitted to Langmuir, Freundlich and Dubinin-Radushkevich-Kaganer (DRK) models.

Langmuir equation describes the monolayer adsorption and allows the calculation of the maximum amount adsorbed to complete the monolayer $\left(q_{\max }\right.$ in $\left.\mathrm{mg} \mathrm{g}^{-1}\right){ }^{20}$ Its expression is:

$$
\frac{C_{\mathrm{e}}}{q_{\mathrm{e}}}=\frac{1}{b \times q_{\max }}+\frac{C_{\mathrm{e}}}{q_{\max }}
$$

where $C_{\mathrm{e}}$ is the liquid phase solute equilibrium concentration $\left(\mathrm{mg} \mathrm{L}^{-1}\right), q_{\mathrm{e}}$ is the adsorbed amount of solute per unit gram of adsorbent $\left(\mathrm{mg} \mathrm{g}^{-1}\right)$ and $b\left(\mathrm{~L} \mathrm{mg}^{-1}\right)$ is the Langmuir adsorption constant which is related to the energy of adsorption.

Freundlich model ${ }^{21}$ is an empirical model and assumes that the adsorption occurs on a heterogeneous surface. It is described as:

$$
q_{\mathrm{e}}=k_{\mathrm{f}} \times C_{\mathrm{e}}^{1 / n_{\mathrm{f}}}
$$

where $k_{\mathrm{f}}$ and $n_{\mathrm{f}}$ are Freundlich constants and are dependent on the solute-adsorbent interaction.

DRK model ${ }^{22}$ is described by the equation:

$$
q_{\mathrm{e}}=q_{\mathrm{DRK}} \times \exp \left\{-\left[\frac{R T}{E_{\mathrm{S}}}\left(\ln \frac{C_{\mathrm{sat}}}{C_{\mathrm{e}}}\right)\right]^{n}\right\}
$$

where $T$ is the temperature and $R$ is the gas constant. Considering $n=4$ and the $C_{\text {sat }}$ equal to the solubility in water of the solute $\left(\mathrm{mg} \mathrm{L}^{-1}\right)$, it is possible to determine the $q_{\text {DRK }}$ which is the limiting amount filling the micropores at equilibrium $\left(\mathrm{mol} \mathrm{g}^{-1}\right)$ and $E_{\mathrm{S}}$ that is the characteristic energy of adsorption $\left(\mathrm{J} \mathrm{mol}^{-1}\right) \cdot{ }^{22}$

\section{Results and discussion}

\subsection{Textural and chemical characterization of adsorbents}

Fig. 1 depicts the TEM images of the R-KC adsorbent and its precursor (rape straw). The raw material presents a homogeneous amorphous structure and the $\mathrm{R}-\mathrm{KC}$ image reveals that the chemical activation process by $\mathrm{K}_{2} \mathrm{CO}_{3}$ provokes a slightly
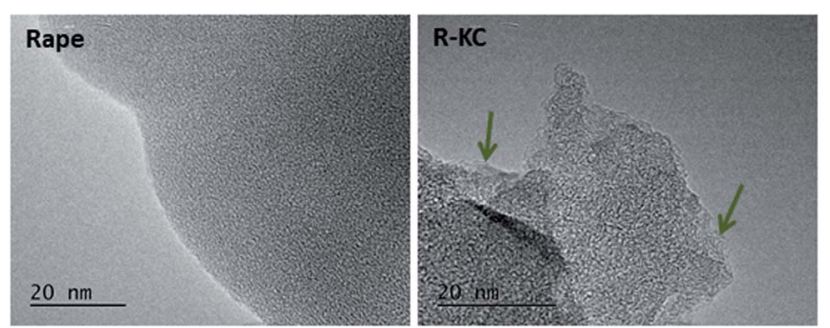

Fig. 1 TEM images of rape straw (left) and R-KC material (right).

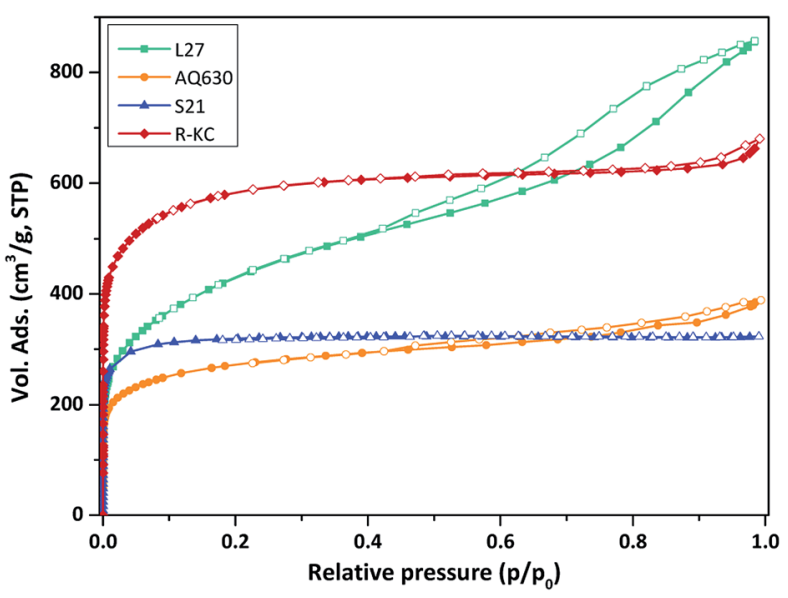

Fig. 2 Nitrogen adsorption/desorption isotherms at $77 \mathrm{~K}$ of the studied adsorbents. Close symbols represent adsorption and empty symbols represent desorption.

expansion of the structure with formation of small ordered regions (indicated by arrows in the figure).

Fig. 2 shows the $\mathrm{N}_{2}$ adsorption/desorption isotherms obtained at $77 \mathrm{~K}$ for all the adsorbents. The four activated carbons are clearly different in terms of porous properties. AQ630, S21 and R-KC samples present a Type I(a) isotherm according to the IUPAC classification, ${ }^{23}$ characteristic of microporous materials, while, L27 shows a Type IV isotherm with a prominent hysteresis loop above 0.4 of relative pressure, typical for micromesoporous materials. The highest surface area was obtained for R-KC $\left(2200 \mathrm{~m}^{2} \mathrm{~g}^{-1}\right)$ that results twice the value of AQ630 (Table 2). The micropore volume was found between 0.38 and $0.83 \mathrm{~cm}^{3} \mathrm{~g}^{-1}$ following the trend: R-KC > L27 > S21 > AQ630. According to the isotherm, sample L27 shows the highest mesoporous development with a volume of $0.79 \mathrm{~cm}^{3} \mathrm{~g}^{-1}$; for samples AQ630 and R-KC similar mesoporous volumes were obtained ( $c a .0 .20 \mathrm{~cm}^{3} \mathrm{~g}^{-1}$ ) and $\mathrm{S} 21$ does not show the presence of mesopores, it is only microporous.

Chemical composition of the adsorbents was evaluated by elemental analysis (Table 2) showing important differences on the $\mathrm{O}$ amounts that were higher for samples $\mathrm{L} 27$ and $\mathrm{R}-\mathrm{KC}$, this is in concordance with the surface $\mathrm{pH}$ (and thermogravimetric profiles, Fig. S2 ESI $\dagger$ ) that reveals the slightly acidic character for these two adsorbents, while the materials AQ630 and S21 presented neutral-basic character. 
Table 2 Textural parameters obtained from the $\mathrm{N}_{2}$ isotherms at $77 \mathrm{~K}$, chemical composition obtained from elemental analysis (wt\%) and surface $\mathrm{pH}$ of all the adsorbents

\begin{tabular}{|c|c|c|c|c|c|c|c|c|c|c|c|}
\hline Sample & $\begin{array}{l}S_{\mathrm{BET}} \\
\left(\mathrm{m}^{2} \mathrm{~g}^{-1}\right)\end{array}$ & $\begin{array}{l}V_{\text {total }}{ }^{a} \\
\left(\mathrm{~cm}^{3} \mathrm{~g}^{-1}\right)\end{array}$ & $\begin{array}{l}W_{0}{ }^{b} \\
\left(\mathrm{~cm}^{3} \mathrm{~g}^{-1}\right)\end{array}$ & $\begin{array}{l}L^{c} \\
(\mathrm{~nm})\end{array}$ & $\begin{array}{l}W_{\text {meso }}{ }^{d} \\
\left(\mathrm{~cm}^{3} \mathrm{~g}^{-1}\right)\end{array}$ & $W_{\text {meso }} / W_{0}$ & $\begin{array}{l}C \\
(\mathrm{wt} \%)\end{array}$ & $\begin{array}{l}\mathrm{N} \\
\text { (wt\%) }\end{array}$ & $\begin{array}{l}\mathrm{O} \\
(\mathrm{wt} \%)\end{array}$ & $\mathrm{O} / \mathrm{C}$ & $\begin{array}{l}\text { Surface } \\
\mathrm{pH}\end{array}$ \\
\hline L27 & 1573 & 1.350 & 0.532 & 2.20 & 0.793 & 1.49 & 89.1 & $<0.02$ & 5.2 & 0.06 & 5.68 \\
\hline S21 & 1266 & 0.500 & 0.455 & 0.93 & 0.000 & 0.00 & 93.1 & $<0.02$ & 2.2 & 0.02 & 7.34 \\
\hline $\mathrm{R}-\mathrm{KC}$ & 2220 & 1.047 & 0.832 & 1.23 & 0.130 & 0.16 & 86.4 & $<0.02$ & 6.6 & 0.08 & 6.55 \\
\hline
\end{tabular}

${ }^{a}$ Evaluated at $p / p_{0} \sim 0.99 .{ }^{b}$ Evaluated by DR method. ${ }^{c}$ Evaluated by Stoeckli-Ballerini equation. ${ }^{d}$ Evaluated by the 2D-NLDFT-HS method.

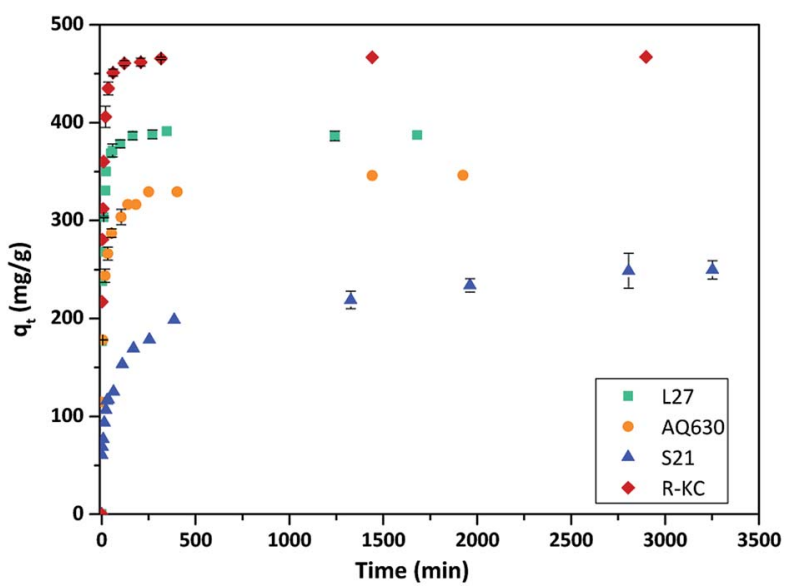

Fig. 3 Evolution of Rac-metolachlor adsorption as a function of the contact time at $25^{\circ} \mathrm{C}$ for the four adsorbents. The error bars represent the standard deviation.

\subsection{Adsorption of Rac-metolachlor: kinetics and isotherms}

Fig. 3 and S3 ESI $\dagger$ show the rate of the Rac-metolachlor adsorption on the four studied materials; in all cases the same concentration ( $25 \mathrm{mg} \mathrm{\textrm {L } ^ { - 1 }}$ ) and adsorbent amount $(5 \mathrm{mg}$ ) were employed. An increase in the adsorption time implies an increase in the removal of Rac-MET before equilibrium was reached. Similar kinetic profiles were obtained regardless the nature of the carbonaceous adsorbent, although the uptake at equilibrium conditions was very different for each adsorbent. For the AQ630, L27 and R-KC carbon materials, the adsorption was relatively fast, reaching the equilibrium after $c a .3 \mathrm{~h}$, however the equilibrium for S21 was reached after $c a .6 \mathrm{~h}$. This fact can be associated to the absence of mesopores, since its presence facilitates the adsorption of the molecule during the first steps - they are able to provide a short path for the molecule diffusion inside the porosity of the activated carbon (from the mesopores to the micropores). ${ }^{24}$ The experimental data were fitted by a non-linear pseudo-first and pseudo-second order kinetic models. ${ }^{\mathbf{1 6 - 1 8}}$ As shown in Table 3, the correlation coefficients, $R^{2}$, for the pseudo-second order kinetics model $(0.882-$ 0.995) were best fitted than those for the pseudo-first order model (0.777-0.954), additionally, the calculated $q_{\mathrm{e}}$ values are closer to the experimental ones indicating that the adsorption mechanism is governed by the pseudo-second order regime for all the studied adsorbents. The highest value of the rate constant was obtained for the adsorption on L27 $\left(0.055 \mathrm{~g} \mathrm{mg}^{-1}\right.$ $\mathrm{h}^{-1}$ ), while similar values were obtained for AQ630 and R-KC (0.034 and $0.047 \mathrm{~g} \mathrm{mg}^{-1} \mathrm{~h}^{-1}$, respectively). This confirms that the presence of the mesopores (transport pores) increases the adsorption rate, since $\mathrm{L} 27$ presents the higher mesoporous development while AQ630 and R-KC show similar mesoporous volume. S21 has no development of mesopores showing the lower rate constant $\left(0.010 \mathrm{~g} \mathrm{mg}^{-1} \mathrm{~h}^{-1}\right)$. The highest adsorption capacity was obtained for R-KC (reaching 99\% of adsorption at equilibrium time) followed by L27, AQ630 and S21 (Fig. 3, S3 ESI $\dagger$ and Table 3). These differences could be associated to the different textural parameters of the adsorbents, particularly in their micro and mesoporous networks. Furthermore, the pore size (Table 2) has an important effect on the adsorption process since the activated carbon with lower pore size (S21) presents the lower adsorption.

The adsorption mechanism of the Rac-MET on the four activated carbons was also analysed applying the intraparticle diffusion model. For all adsorbents, the $q_{t} v s . t^{1 / 2}$ plots exhibited a multi-linearity character (Fig. S4 ESI $\dagger$ ), revealing the existence of two steps in the adsorption process. For the first linear stage, the adsorption of Rac-MET involves intraparticle diffusion (diffusion into the pores of the adsorbent), however, any curve passed through the origin, indicating that the rate-determining step is governed by several sorption mechanisms. ${ }^{25}$ The second stage corresponds to the final equilibrium step marked by an almost constant $q_{t}$, due to the low Rac-MET concentration in solution. The rate constant, $k_{\mathrm{p}}$, calculated from the first stage (Table 3) may classified as follows: $k_{\mathrm{p}}(\mathrm{R}-\mathrm{KC}) \sim k_{\mathrm{p}}(\mathrm{L} 27)>$ $k_{\mathrm{p}}(\mathrm{AQ} 630)>k_{\mathrm{p}}(\mathrm{S} 21)$. The smallest value for the $\mathrm{S} 21$ indicates that this activated carbon presents the lowest intraparticle diffusion rate that can be justified by the absence of mesopores.

Further information about the adsorption mechanism can be obtained analysing the adsorption isotherms (Fig. 4). According to the Giles classification, ${ }^{26}$ all the adsorbents presented a L type isotherm, concave to the concentration axis with a defined plateau. This type of adsorption isotherms is associated to a monolayer adsorption with no strong competition of the solvent and without interactions between adsorbed molecules. The adsorption capacity values were found similar for AQ630 and S21 (423 and $485 \mathrm{mg} \mathrm{g}^{-1}$, respectively) and higher values were obtained for L27 $\left(633 \mathrm{mg} \mathrm{g}^{-1}\right)$ and R-KC (1178 mg $\left.\mathrm{g}^{-1}\right)$. These differences are mainly associated to the textural 


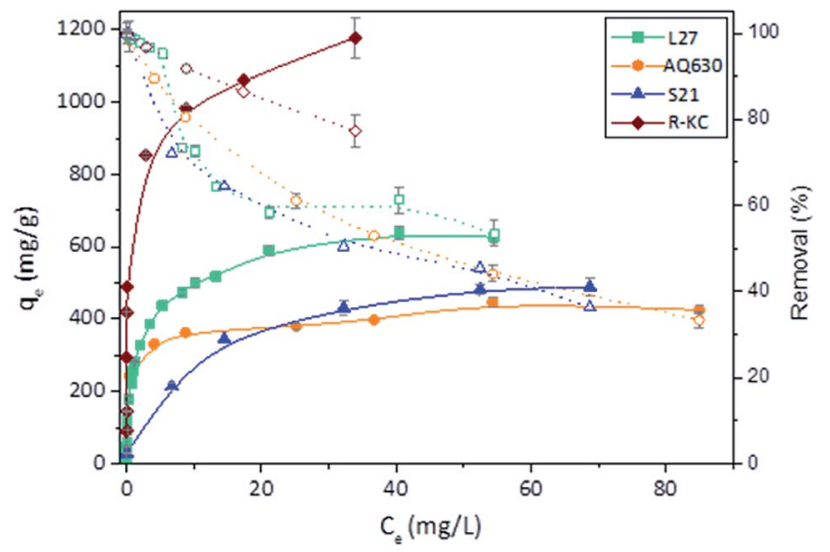

Fig. 4 Rac-metolachlor experimental isotherms (filled symbols) and percentage removal (open symbols) of the four adsorbents at $25^{\circ} \mathrm{C}$. The error bars represent the standard deviation.

development of the activated carbons, being the material with the highest surface area (R-KC, Table 2) the adsorbent with greater adsorption capacity. Additionally, S21 showed the less steep slope at low concentration range suggesting a weaker adsorption under low amount of solute. These adsorption isotherms point out the importance of the combining presence of micro and mesopores to favour the adsorption.

The experimental isotherms were fitted to theoretical Langmuir, Freundlich and Dubinin-Radushkevich-Kaganer (DRK) models, the fitted parameters are collected in Table 4. The regression coefficient values revealed similar goodness of fitting for Freundlich model $\left(R^{2}\right.$ between 0.95 and 0.98$)$ for all the adsorbents. With the exception of S21, the values of amount adsorbed to complete the monolayer obtained by Langmuir model $\left(q_{\max }\right)$ are close to the experimental amount adsorbed at equilibrium values. Furthermore, the fitting of the experimental data to the DRK model revealed $q_{\text {DRK }}$ values (theoretical adsorption capacity on the micropores) slightly lower to the $q_{\text {e,exp }}$ with the exception of S21 (purely microporous material) indicating that the adsorption of the Rac-MET takes place in both micro and mesoporous surface. Additionally, the calculation of the occupied microporous volume, by the equation: ${ }^{22}$ $W_{\mathrm{o}(\mathrm{occ})}=\left(\mathrm{q}_{\mathrm{DRK}} \times V_{\text {molar }}\right) / W_{0}$, showed high percentage of occupied microporous surface being 96, 95, 99 and over $100 \%$ for L27, AQ630, S21 and R-KC. This fact reveals that the four studied adsorbents present an accessible microporosity for the adsorption of Rac-MET and confirms that the differences on the experimental adsorption capacities between them are related to the presence of mesopores.

L27 and AQ630 were selected to study the influence of the solution $\mathrm{pH}$ during adsorption, due to its different acidic properties (Table 2). The natural $\mathrm{pH}$ of the Rac-MET was $c a .6$ and the adjustment to 2 (with $\mathrm{HCl} 0.1 \mathrm{M}$ ) was made to analyse the effect of the media acidification. No significant differences were obtained between both solutions pH (Fig. S5 ESI†) indicating that the adsorption of Rac-MET was not affected by the $\mathrm{pH}$, discarding the electrostatic interactions as expected due to the non-polar character of the molecule. Indeed the adsorption would occur through $\pi-\pi$ dispersive interactions between the 
Table 4 Parameters obtained by non-linear fitting to Langmuir, Freundlich and Dubinin-Radushkevich-Kaganer (DRK) isotherms for Rac-MET, S-MET (60\%) and S-MET (100\%) on studied carbonaceous adsorbents

\begin{tabular}{|c|c|c|c|c|c|c|c|c|c|c|c|}
\hline Molecule & Adsorbent & $\begin{array}{l}q_{\mathrm{e}, \exp } \\
\left(\mathrm{mg} \mathrm{g}^{-1}\right)\end{array}$ & $\begin{array}{l}q_{\max } \\
\left(\mathrm{mg} \mathrm{g}^{-1}\right)\end{array}$ & $\begin{array}{l}b \\
\left(\mathrm{~L} \mathrm{mg}^{-1}\right)\end{array}$ & $R^{2}$ & $n_{\mathrm{f}}$ & $\begin{array}{l}k_{\mathrm{f}} \\
\left(\mathrm{mg}^{1-n_{\mathrm{f}}} \mathrm{L}^{n / g}\right)\end{array}$ & $R^{2}$ & $\begin{array}{l}q_{\mathrm{DRK}} \\
\left(\mathrm{mg} \mathrm{g}^{-1}\right)\end{array}$ & $\begin{array}{l}E_{\mathrm{s}} \\
\left(\mathrm{J} \mathrm{mol}^{-1}\right)\end{array}$ & $R^{2}$ \\
\hline \multirow[t]{3}{*}{ Rac-MET } & $\mathrm{L} 27$ & $633 \pm 14$ & $582 \pm 31$ & $0.835 \pm 0.040$ & 0.964 & $4.03 \pm 0.10$ & $266 \pm 14$ & 0.977 & $571 \pm 25$ & $16846 \pm 830$ & 0.964 \\
\hline & AQ630 & $423 \pm 10$ & $402 \pm 22$ & $3.17 \pm 0.10$ & 0.753 & $9.65 \pm 0.50$ & $279 \pm 11$ & 0.936 & $407 \pm 21$ & $20063 \pm 1000$ & 0.825 \\
\hline & $\mathrm{S} 21$ & $485 \pm 5$ & $570 \pm 32$ & $0.097 \pm 0.002$ & 0.991 & $3.25 \pm 0.30$ & $140 \pm 8$ & 0.968 & $506 \pm 27$ & $10981 \pm 540$ & 0.992 \\
\hline & AQ630 & $547 \pm 7$ & $470 \pm 24$ & $5.58 \pm 0.40$ & 0.809 & $6.96 \pm 0.40$ & $267 \pm 14$ & 0.924 & $473 \pm 25$ & $21115 \pm 900$ & 0.821 \\
\hline & $\mathrm{S} 21$ & $463 \pm 3$ & $560 \pm 11$ & $0.076 \pm 0.001$ & 0.964 & $2.93 \pm 0.10$ & $116 \pm 7$ & 0.943 & $482 \pm 26$ & $10437 \pm 500$ & 0.968 \\
\hline & $\mathrm{R}-\mathrm{KC}$ & $970 \pm 8$ & $920 \pm 41$ & $1.85 \pm 0.10$ & 0.898 & $6.49 \pm 0.30$ & $536 \pm 24$ & 0.903 & $928 \pm 47$ & $18606 \pm 950$ & 0.939 \\
\hline \multirow[t]{3}{*}{ S-MET (100\%) } & L27 & $940 \pm 16$ & $1043 \pm 53$ & $0.279 \pm 0.010$ & 0.987 & $3.03 \pm 0.10$ & $329 \pm 16$ & 0.965 & $985 \pm 52$ & $13662 \pm 700$ & 0.987 \\
\hline & AQ630 & $778 \pm 12$ & $785 \pm 41$ & $0.18 \pm 0.03$ & 0.965 & $3.51 \pm 0.20$ & $237 \pm 9$ & 0.997 & $724 \pm 35$ & $12715 \pm 610$ & 0.954 \\
\hline & $\mathrm{S} 21$ & $290 \pm 4$ & $271 \pm 12$ & $3.50 \pm 0.40$ & 0.880 & $7.41 \pm 0.30$ & $162 \pm 9$ & 0.830 & $285 \pm 21$ & $19463 \pm 980$ & 0.978 \\
\hline
\end{tabular}

aromatic ring of the herbicide and $\pi$-electrons of the adsorbent structure. Similar observation was made for the adsorption of $S$ metolachlor on mesoporous resins. ${ }^{27}$

\subsection{Adsorption of $\boldsymbol{S}$-metolachlor: kinetics and isotherms}

Fig. 5 and S6 ESI $\uparrow$ show the kinetic profile obtained for the four studied adsorbents employing different enantiomeric mixtures of metolachlor (Rac-MET, S-MET (60\%) and S-MET (100\%)). Interesting results can be observed as a function of the employed adsorbent. In the case of S21 and R-KC no significant differences were observed as a function of the enantiomer proportion indicating that, for these adsorbents, the adsorption is not selective. However, for the L27 and AQ630 different adsorption capacity was observed as a function of enantiomer's proportion. For L27, when the pure $S$-enantiomer is employed the adsorption at equilibrium increases from 390 to $485 \mathrm{mg} \mathrm{g}^{-1}$, while between $50 \%$ and $60 \%$ of $S$-enantiomer no difference was observed (Fig. 5, S6 ESI $\dagger$ and Table 3). For AQ630 the selectivity is more pronounced suffering an increase from 340 to $405 \mathrm{mg}$ $\mathrm{g}^{-1}$ when the $S$-concentration is increased in $10 \%$ and when the pure $S$ - is employed, the adsorption goes up to $505 \mathrm{mg} \mathrm{g}^{-1}$. In spite of the change in the adsorbed amount at equilibrium time, the shape of the adsorption kinetics was not suffered any modification, indicating that the followed adsorption process
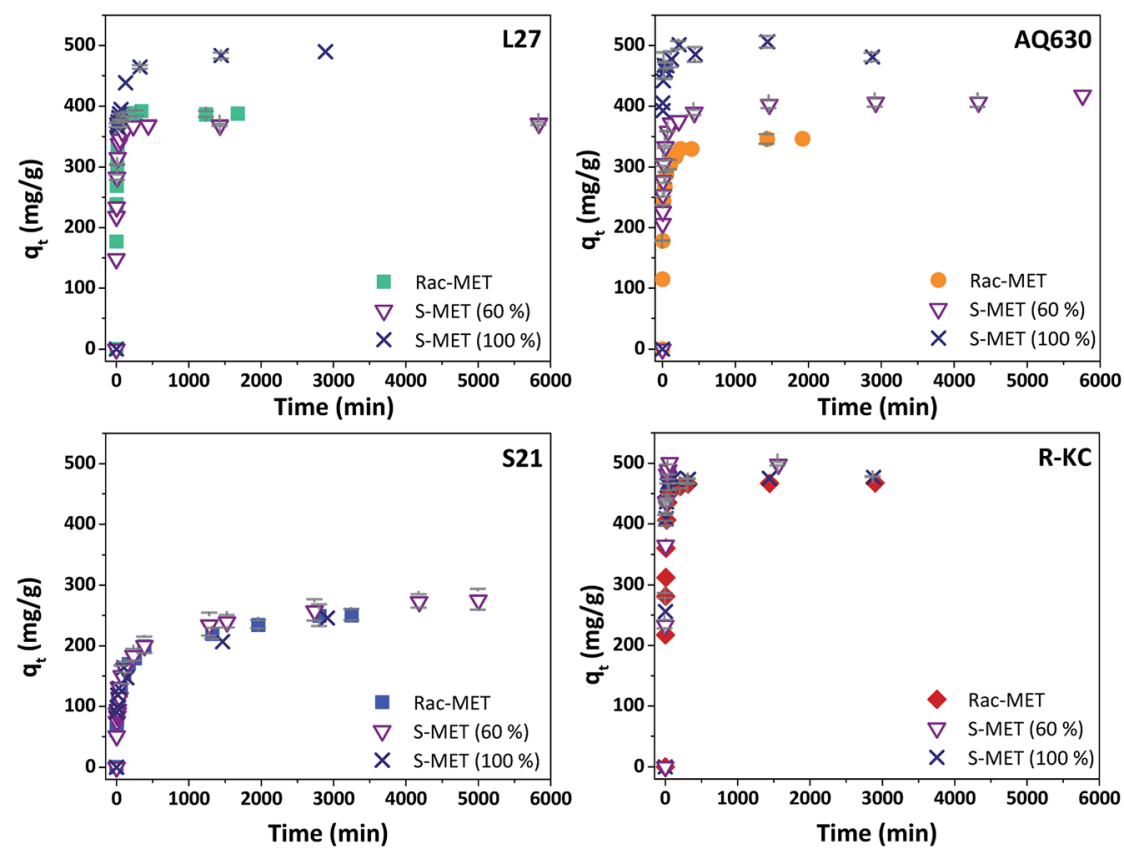

Fig. 5 Evolution of Rac-metolachlor, S-metolachlor (60\%) and S-metolachlor (100\%) adsorption as a function of the contact time at $25{ }^{\circ} \mathrm{C}$ for the four adsorbents. The error bars represent the standard deviation. 

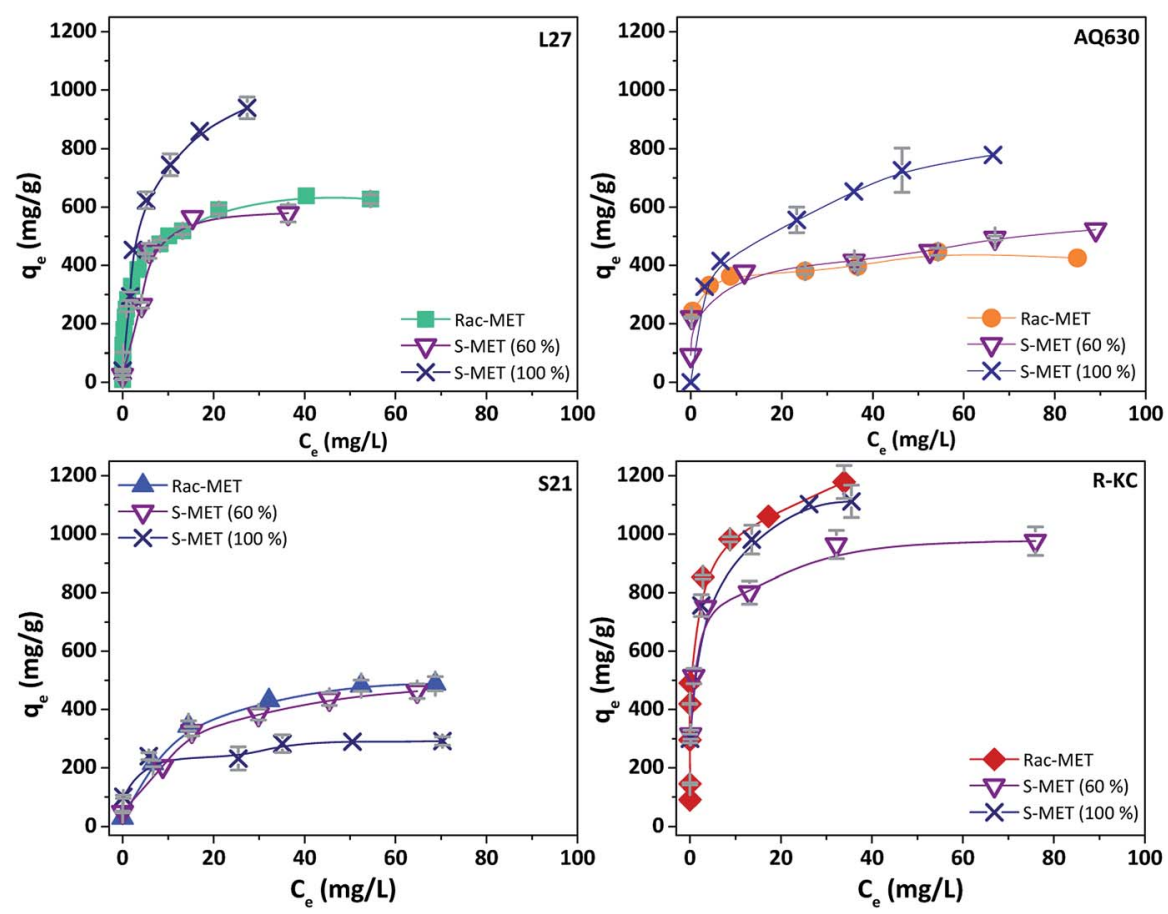

Fig. 6 Experimental isotherms of Rac-metolachlor, S-metolachlor (60\%) and S-metolachlor (100\%) at $25^{\circ} \mathrm{C}$ for the four adsorbents. The error bars represent the standard deviation.

was not varied as a function of the enantiomer's proportion adsorbed. Indeed, in all cases, the kinetic adsorption followed a pseudo-second order model as is indicated by the fitting parameters (Table 3).

To further investigate this behaviour, Fig. 6 and S7 ESI $\uparrow$ show the adsorption isotherms for all studied adsorbents employing the three enantiomer's mixtures. As was previously observed on the kinetics adsorption, important increase on the adsorption capacity was observed when the $S$-enantiomer is employed for adsorption on L27 and AQ630 materials. On the other hand, for S21 and R-KC adsorbents, slightly differences were also observed at high concentration range.

To understand the adsorption process of the aromatic compounds, it is necessary to take into account the molecular dimension and orientation of the herbicides. ${ }^{28}$ In the case of enantiomers, since they have the same molecular weight, the different orientation could be the reason of the differences on the adsorption capacities. Metolachlor presents two chiral elements, an asymmetrically-substituted carbon atom, and a chiral axis (C-N bond). The presence of the chiral carbon atom results in two enantiomers ( $R$ - and $S$-). Additionally, the carbonyl group can be located away or toward the phenyl ring (positioned perpendicularly respect to the amidyl group) rendering four atropisomers: $a S 1^{\prime} S ; a R 1^{\prime} S ; a S 1^{\prime} R$ and $a R 1^{\prime} R$ (Fig. S8 ESI $\dagger$ ).9, ${ }^{99,30}$ The conformation in which the molecule is adsorbed is important to be considered since it could induce changes on the electronic cloud and consequently it will have influence in the $\pi-\pi$ interactions responsible for the adsorption process.
The samples that showed the highest effect of the enantioselective adsorption (L27 and AQ630) are the activated carbons with higher mesopore volume (Table 2) showing the percentage of occupied microporous surface close to $100 \%$ (see Section 3.2). This fact indicates that the founded differences on the adsorption capacity as a function of adsorbed enantiomer at samples L27 and AQ630 are mainly caused by the accessibility to the larger pores. According to our findings, the S-MET could adopt the adequate conformation to be greater retained in the mesoporous surface, compared with the R-MET, favouring the dispersive interactions between the herbicide and the activated carbon surface and increasing the adsorption capacity obtained.

\section{Conclusions}

Four activated carbons have been employed to study the adsorption of metolachlor herbicide frequently detected in both surface water and groundwater. The adsorbents presented different textural properties in terms of BET area, micro and mesoporous volumes and similar chemical composition. The adsorption uptakes revealed that the mesoporous structure combined with the presence of microporosity is a determining factor in the adsorption capacity. The R-KC carbon presented the higher adsorption of the herbicide associated to its high BET area and the micro/mesoporous network. The acidification of the aqueous media did not render changes on the adsorption capacities pointing out that the adsorption of metolachlor is mainly occurring through non-electrostatic interactions. Interestingly, we have observed an enantioselective adsorption as 
a function of used carbon material. In the case of L27 and AQ630 adsorbents, the enantiomer $S$-metolachlor is greater adsorbed indicating that the $S$-isomer of the molecule adopts the adequate conformation to be retained in the mesoporous structure. This finding supposes an interesting achievement since the S-MET is the most active enantiomer as herbicide and the selective adsorption will allow the recover, separation and purification of the herbicide.

\section{Conflicts of interest}

There are no conflicts to declare.

\section{Acknowledgements}

This work was co-financed by the European Union and the Conseil Regional du Centre-Val de Loire region through the European Regional Development Fund. We gratefully acknowledge the financial support provided by the PIVOTS project and the Conseil Regional du Centre-Val de Loire (ARD 2020 program and CPER 2015-2020), the French Ministry of Higher Education and Research (CPER 2015-2020) and subsidy funds from CNRS and University of Orleans and the Centre Val de Loire Region. This work has been carried out as part of the regional project DEPRICAME.

\section{References}

1 C. A. Orge, M. F. R. Pereira and J. L. Faria, Chem. Eng. J., 2017, 318, 247.

2 V. A. Sakkas, I. M. Arabatzis, I. K. Konstantinou, A. D. Dimou, T. A. Albanis and P. Falaras, Appl. Catal., B, 2004, 49, 195.

3 M. Bosetto, P. Arfaioli and P. Fusi, Sci. Total Environ., 1992, 123/124, 101.

4 S. P. Acharya, L. Johnson and J. Weidhaas, J. Environ. Sci., 2020, 89, 23.

5 M. Etcheverry, V. Cappa, J. Trelles and G. Zanini, Chem. Eng. J., 2017, 5, 5868.

6 A. Thiam and R. Salazar, Environ. Sci. Pollut. Res., 2019, 26, 2580.

7 D. R. V. Guelfi, F. Gozzi, A. Machulek, I. Sires, E. Brillas and S. C. Oliveira, Catal, 2018, 313, 182.

8 P. O'Connell, C. T. Harms and J. R. F. Allen, Crop Prot., 1998, 17, 207.

9 H. Moser, G. Rihs, H. P. Sauter and B. Böhner, Pesticide Chemistry, Human Welfare and Environment, 1983, p. 315.

10 JORF 2002, Avis aux fabricants, distributeurs et utilisateurs de produits phytopharmaceutiques vises par le décret no
94-359 du 5 mai 1994 relatif au contrôle des produits phytopharmaceutiques, Journal Officiel de la République Française, 2002, 192, 13961-13963.

11 D. L. Shaner, G. Brunk, D. Belles, P. Westra and S. Nissen, Pest Manage. Sci., 2006, 62, 617.

12 World Health Organization, Guidelines for Drinking-Water Quality, Geneva, 4th edn, 2011, available at https://apps.who.int/iris/bitstream/handle/10665/44584/ 9789241548151_eng.pdf;jsessionid=909489238E 6ED36CF132D8C4D3A34044? sequence $=1$, accessed in 30 March 2020.

13 R. Otero, M. I. López, D. Esquivel, J. M. Fernández and F. J. Romero-Salguero, Microporous Mesoporous Mater., 2019, 278, 35.

14 W. F. Heydens, I. C. Lamb and A. G. E. Wilson, Hayes' Handbook of pesticide toxicology (Third Edition), Academic Press, 2010.

15 A. Dabrowski and M. Jaroniec, Adv. Colloid Interface Sci., 1990, 31, 155.

16 S. Lagergren, K. Sven. Vetenskapsakad. Handl., 1898, 24, 1.

17 Y. S. Ho and G. McKay, Water Res., 2000, 34, 735.

18 Y. S. Ho, J. Hazard Mater., 2006, 136, 681.

19 W. J. Weber and J. C. Morris, J. Sanit. Eng. Div., Am. Soc. Civ. Eng., 1963, 89, 31.

20 I. Langmuir, J. Am. Chem. Soc., 1918, 40, 1361.

21 H. M. F. Freundlich, Z. Phys. Chem., 1906, 57, 385.

22 F. Stoeckli, M. V. López-Ramón and C. Moreno-Castilla, Langmuir, 2001, 17, 3301.

23 M. Thommes, K. Kaneko, A. V. Neimark, J. P. Olivier, F. Rodriguez-Reinoso, J. Rouquerol and K. S. W. Sing, Pure Appl. Chem., 2015, 87, 1051.

24 C.-T. Hsieh and H. Teng, Carbon, 2000, 38, 863.

25 V. J. P. Poots, G. McKAy and J. J. Healy, J.-Water Pollut. Control Fed., 1978, 50, 926.

26 C. H. Giles, T. H. MacEwan, S. N. Nakhwa and D. Smith, J. Chem. Soc., 1960, 3973.

27 R. Otero, D. Esquivenl, M. A. Ulibarri, F. J. Romero Salguero, P. Van Der Voort and J. M. Fernández, Chem. Eng. J., 2014, 251, 92.

28 S.-S. Chen, J. S. Taylor, L. A. Mulford and C. D. Norris, Desalination, 2004, 160, 103-111.

29 I. Alkorta, J. Elguero, C. Roussel, N. Vanthuyne and P. Piras, Adv. Heterocycl. Chem., 2012, 105, 1-188.

30 Z. Salta, A. M. Kosmas and O. N. Ventura, Theor. Chem. Acc., 2018, 137, 151. 